\title{
Delay of Disease Development in Transgenic Petunia Plants Expressing Cucumber Mosaic Virus $\mathrm{I}_{17} \mathrm{~N}-$ Satellite RNA
}

\author{
Shin Je Kim and Kyung-Hee Paek' \\ Plant Molecular Biology Laboratory, Genetic Engineering Research Institute, Korea Institute of Science \\ and Technology, P.O. Box 115, Yusung, Taejon,305-600, Korea
}

Byung-Dong Kim

Department of Horticulture, Seoul National University, Suwon, 441-744, Korea

Additional index words. Petunia hybrida, 'Bluepicotti', satellite RNA, mediated protection, tissue culture, transformation

\begin{abstract}
A cDNA clone of cucumber mosaic virus (CMV) $1_{17} \mathrm{~N}$-satellite RNA driven by the cauliflower mosaic virus (CaMV) 35S transcript promoter, was stably integrated into the genome of Petunia hybrida 'Bluepicoti' tissues by Agrobacterium tumefaciens Ti plasmid-mediated transformation. Transgenic plants producing CMV satellite RNA showed delayed disease development when inoculated with CMV-Y, a helper virus for the $I_{17} N$-satellite RNA. Furthermore, transgenic petunia plants showed delayed disease development against tobacco mosaic virus (TMV), a tobamovirus not related to CMV. Northern blot analysis revealed that large amounts of unit length satellite RNA (335 bp) were produced in CMV-infected transgenic petunia plants; whereas, mainly transcripts driven by the CaMV $35 \mathrm{~S}$ promoter (approximately $1 \mathrm{~kb}$ ) were produced in TMV-infected transgenic plants. SDS-PAGE and Western blotting showed that symptom reduction was correlated with a reduction in the amount of viral coat protein in transgenic plants.
\end{abstract}

Cucumber mosaic virus (CMV) is an economically important plant virus because of its large number of different strains, its worldwide distribution, and its numerous hosts, nearly 800 plant species (Collmer and Howell, 1992; Rizzo and Palukaitis, 1988). Symptoms induced by CMV infection include stunting, mottling, discoloration, and distortion of leaves, flowers, and fruit. Infected plants may be greatly reduced in size or killed. Crop yields are reduced along with reduced quality (Fraser, 1986). Agronomic practices, such as seed treatment, sanitation, or cross-protection with attenuated strains, have not been completely effective methods of control of CMV.

CMV belongs to the genus Cucumovirus in the family Bromoviridae. It has a tripartite genome consisting of singlestranded plus-sense RNAs (Peden and Symons, 1973) and four open reading frames (ORFs). RNAs 1 and 2 each contain one ORF encoding proteins of 111 and $97 \mathrm{kDa}$, respectively, that are required for replication (Hayes and Buck, 1990; Nitta et al., 1988). RNA 3 contains two ORFs: the 5' end of RNA 3 encodes a $30-\mathrm{kDa}$ protein involved- in viral movement and the $3^{\prime}$ end of RNA 3 generates a subgenomic RNA, RNA 4, which acts as a messenger for the viral coat protein (Gould and Symons, 1977). In addition to genomic RNA, some CMV isolates contain extra RNA species of 330 to 380 nucleotides termed satellite RNAs (Francki, 1985; Fritsch and Mayo, 1989). Satellite RNAs are totally dependent on their helper viruses for replication and encapsidation (Kuwata et al., 1991; Masuta and Takanami, 1989; Murant and Kumar, 1990;

Received for publication 27 July 1994. Accepted for publication 31 Oct. 1994. We thank Eun Kyung Park (Korea Ginseng and Tobacco Research Institute) for the gift of CMV-Y strain and antisera to CMV-Y and TMV. B.D. Harrison is cordially acknowledged for providing cDNA clone of CMV 117N satellite RNA. We thank J.R. Liu for his critical reading of this manuscript.. Sang-Jik Lee's technical assistance is greatly appreciated. This work was supported in part by a grant (G70300) to K.-H. Pack in aid for scientific research from the Korea Ministry of Science and Technology. The cost of publishing this paper was defrayed in part by the payment of page charges. Under postal regulations, this paper therefore must be hereby marked advertisement solely to indicate this fact.

${ }^{1}$ To whom reprint requests should be addressed.
Naidu et al., 1991; Palukaitis, 1988). The presence of a satellite RNA can alter symptoms caused by the helper virus (Jaegle et al., 1990; Kaper and Collmer, 1988). Generally, satellite RNAs cause attenuation of symptoms, but in some cases can induce severe and different symptoms. The type of symptom modification produced depends on the satellite RNA, the strain of the helper virus, and the host plant (Mossop and Francki, 1977; Wu et al., 1993).

The ability to transform plant genomes with foreign genetic material via the Agrobacterium tumefaciens Ti plasmid system has made it possible to enhance plant resistance to viruses by incorporating virus-related nucleotide sequences into the nuclear genome of the host (Baulcombe et al., 1986; Beachy et al., 1990; Buck, 1991; Harrison et al., 1987; Powell-Abel et al., 1986). Protection of transgenic plants against virus infection has been characterized by a decrease in the number of primary infection sites on inoculated leaves and by a delay or lack of systemic symptom development. We previously demonstrated resistance to CMV in transgenic tobacco plants that express a cDNA copy of $\mathrm{CMV} \mathrm{I}_{17} \mathrm{~N}$-satellite RNA (Kim et al., 1992; Pack and Hahn, 1991).

In an attempt to establish virus-resistant transgenic petunia plants expressing the $\mathrm{CMV} \mathrm{I}_{17} \mathrm{~N}$-satellite $\mathrm{RNA}$, we conducted . virus-resistance assays using CMV-Y, a helper virus for the CMV $\mathrm{I}_{17} \mathrm{~N}$-satellite RNA, and TMV, not a helper virus. In this study, we describe the delayed disease development ability of the $\mathrm{CMV} \mathrm{I}_{17} \mathrm{~N}$ satellite RNA upon CMV-Y inoculation in transgenic petunia plants. In addition, transgenic petunia showed symptom attenuation upon TMV inoculation, which is not a helper virus for the CMV satellite RNA replication.

\section{Materials and Methods}

Materials Restriction endonucleases were purchased from Promega (Madison, Wise.) and used as instructed by the manufacturer. Other chemicals were from Sigma Chemical Co. (St. Louis). $[-32 \mathrm{P}] \mathrm{dCTP}$ was purchased from New England Nuclear (Boston) or Amersham International plc. (Seoul, Korea). Petunia hybrida 'Bluepicoti' was used as plant material. CMV-Y (provided by 
Eun-Kyung Park at Korea Ginseng and Tobacco Research Institute) and TMV (strain isolated from tobacco) were used for challenge inoculation. CMV-Y did not contain any detectable satellite RNA. The plasmid pROK1/105 containing the CMV $\mathrm{I}_{17} \mathrm{~N}$ satellite RNA used in this work was provided by Bryan D. Harrison (Baulcombe et al., 1986). pROK1/105 contains two complete cDNA satellite sequence units in a head-to-tail arrangement. The expression cassette comprises the cauliflower mosaic virus $35 \mathrm{~S}$ RNA promoter and the termination fragment of the nopaline synthase gene of Agrobacterium T-DNA (Trios).

Plant transformation. The plasmid pROK1/105 containing the chimeric $\mathrm{CMV} \mathrm{I}_{17} \mathrm{~N}$ satellite RNA was transformed into the disarmed Agrobacterium tumefaciens strain LBA4404 using the direct DNA uptake method (An, 1987). The structure of the plasmid transferred to $\mathrm{A}$. tumefaciens was verified by purification and restriction digestion analyses. Transformation of petunia plants was based on the method of leaf disk cocultivation with A. tumefaciens (Horsch et al., 1985). Induction of callus and shoot formation were conducted on solid MS medium (Murashige and Skoog, 1962) supplemented with $2.0 \mathrm{mg} \cdot \mathrm{liter}^{-1}$ indole acetic acid, $1.0 \mathrm{mg} \cdot$ liter $^{-1}$ benzyl-aminopurine, and $100 \mathrm{mg} \cdot \mathrm{liter}^{-1} \mathrm{kanamycin}^{-}$ sulfate as a selection agent. For root induction, kanamycin-resistant regenerated shoots were transferred to hormone-free MS medium containing $50 \mathrm{mg} \cdot \mathrm{liter}^{-1} \mathrm{kanamycin}$ After root development ( 2 to 3 weeks), plantlets were transferred to potting soil.

DNA and RNA preparations. Plasmid DNA was prepared from E. coli and A. tumefaciens by the alkaline lysis method (Bimboim, 1983). Genomic DNA was extracted from plant tissues according to the method of Dellaporta et al. ( 1983). Total RNA was extracted from leaves of transgenic and control petunia plants by the guanidinium isothiocyanate method (Chomczynski and Sacchi, 1987).

DNA blot hybridization. DNA samples were digested with ScaI, fractionated by electrophoresis on a $0.8 \%$ agarose gel, and blotted onto a nylon membrane (Hybond $\mathrm{N}$ ). Hybridization was performed for $24 \mathrm{~h}$ at $43 \mathrm{C}$ in $0.1 \%$ SDS, 5x Denhardt's solution,

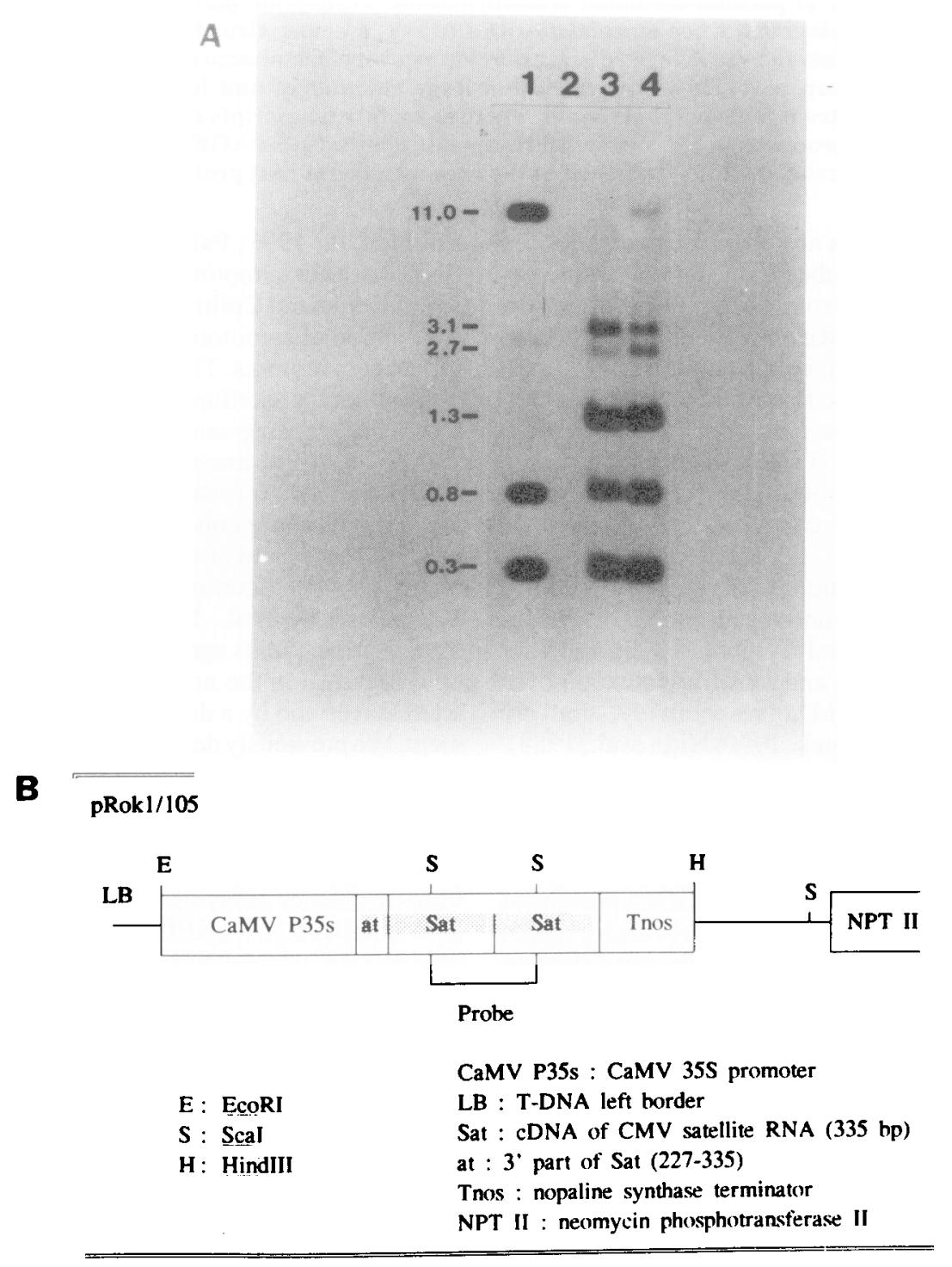

Fig. 1. (A) Southern blot analysis of the cDNA of CMV $\mathrm{I}_{17}$-satellite RNA from transformed petunia plants. Lane 1, ScsI digested pRok1/105; 2, ScaI digested genomic DNA from nontransformed petunia plant; 3, Scale digested genomic DNA from transgenic plant line 1 transformed with pRok1/105; 4, transgenic plant line 2. Approximately $30 \mu \mathrm{g}$ of genomic DNA was loaded on each lane. (B) The probe was a 32P labelled 335bp ScaI cDNA fragment of pRok1/105. The figure shows a region adjacent to the cDNA insert and the expression cassette of pRok1/105. 


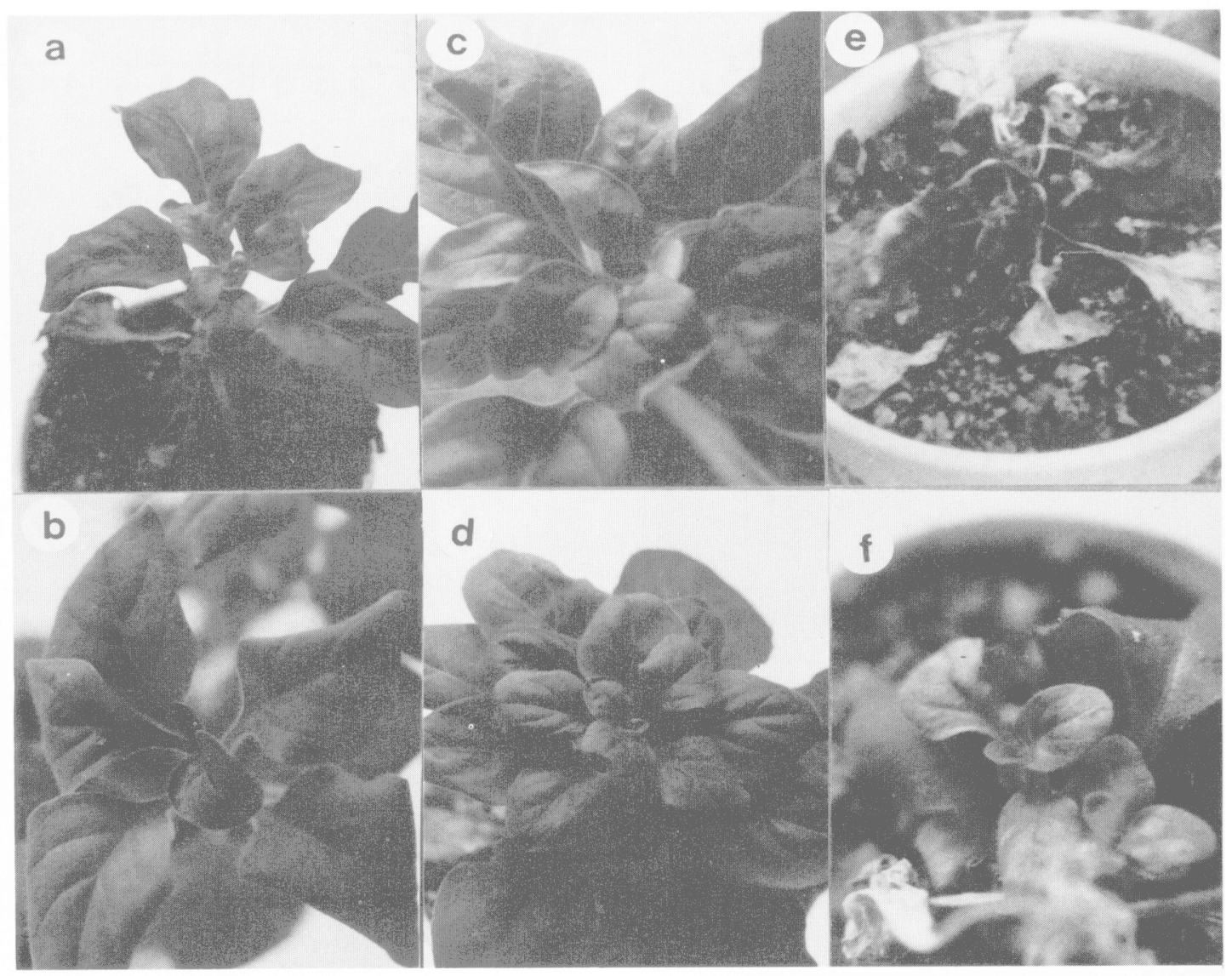

Fig. 2. Symptoms induced by CMV and TMV on nontransformed and transgenic petunia. (A and B) CMV inoculation only; (C and D), TMV inoculation only; (E and F), CMV and TMV coinoculation. Upper the pictures, nontransformed petunia plants lower three pictures, transformed typical petunia plants. Pictures were taken 20 days postinoculation.

5x SSPE, and $100 \mu \mathrm{g} \cdot \mathrm{ml}-1$ sheared, denatured salmon sperm DNA. DNA probe was prepared by labeling a 335-bp ScaI fragment of pROK1/105 with $\left[\alpha^{-32} \mathrm{P}\right] \mathrm{dCTP}$ by the random priming method (Feinberg and Vogelstein, 1983). The membrane was washed with constant agitation in $2 \mathrm{x}$ SSPE and 0.170 SDS for 10 rein; 0.2x SSPE and 0.170 SDS for 5 rein, and 0.1x SSPE and 0.1\% SDS for $5 \mathrm{~min}$ at $43 \mathrm{C}$.

RNA blot hybridization. RNA samples $(20 \mu \mathrm{g})$ from leaves collected 20 days postinoculation, were treated with formaldehyde and formamide according to Sambrook et al. ( 1989). Samples were electrophoresed on a $1.0 \%$ agarose gel containing $0.67 \mathrm{~m}$ formaldehyde and then transferred to a nylon membrane. Hybridization conditions were similar to those used for DNA blotting described above, except temperature was 52C. Membrane filters were exposed to X-ray films with an intensifying screen at $-70 \mathrm{C}$.

Protein analysis. Twenty days after inoculation, leaves of transgenic and nontransformed petunia plants were collected, ground in liquid nitrogen, and homogenized with a mortar and pestle in 2-ml buffer (10 mm sodium phosphate buffer, $\mathrm{pH}$ 7.0) per gram fresh weight. The homogenate was clarified by centrifugation at 12,000 rpm for $10 \mathrm{~min}$ in an Eppendorf centrifuge, and the protein concentration was determined according to the method of Lowry et al. (1951).

Electrophoresis of proteins and immunoblot analysis. Protein extracts were fractionated on 10\% SDS-polyacrylamide gels and either stained with Coomassie brilliant blue or transferred onto a nitrocellulose membrane (Hoefer, San Fernando, Calif.) as de- scribed by Towbin et al. (1979). Antisera to CMV-Y and TMV virions were used at a 1:250 dilution. Immunoblotting was conducted using goat anti-rabbit IgG conjugated with horseradish peroxidase (Sigma).Calorimetric reactions were performed by using dichloronaphtol as a substrate.

Symptom assays of transgenic plants. Seeds from self-fertilized transgenic plants were collected and 100 seeds from each transgenic line were aseptically germinated on an MS medium (Murashige and Skoog, 1962) supplemented with $200 \mathrm{mg} \cdot \mathrm{liter}^{-1}$ kanamycin sulfate, and then kanamycin-resistant and kanamycin-sensitive seedlings were counted. None of the 100 nontransformed seedlings survived on this selection medium. Progenies of self-fertilized transgenic line 1 (100\% germination) survived at an approximate ratio of $15: 1$ on kanamycin-containing medium, suggesting that two copies of T-DNA were inserted in the nuclear genome. Germination ratio could not be accurately estimated for transgenic line 2 ( $\approx 60 \%$ of germination) because of a poor germination rate. About 3 weeks after transfer to potting soil, 10 nontransformed plants and 10 of each transgenic line for each inoculation were used for assays of virus infection. Tw o or three leaves from nontransformed and R1 transgenic plants expressing the cDNA of CMV satellite RNA were dusted with Carborundum (500 mesh) and mechanically inoculated with a crude sap from systemically CMV-Y infected N. tabacum 'w38' leaves prepared in $10 \mathrm{~mm}$ sodium phosphte buffer at a 1 to 1 ratio. Purified TMV was inoculated at a concentration of $3 \mu \mathrm{g} \cdot \mathrm{liter}^{-1}$ in $50 \mathrm{~m}$ of $0.01 \mathrm{M}$ phosphate buffer, $\mathrm{pH}$ 7.2. Two plants of each transgenic petunia line and one 


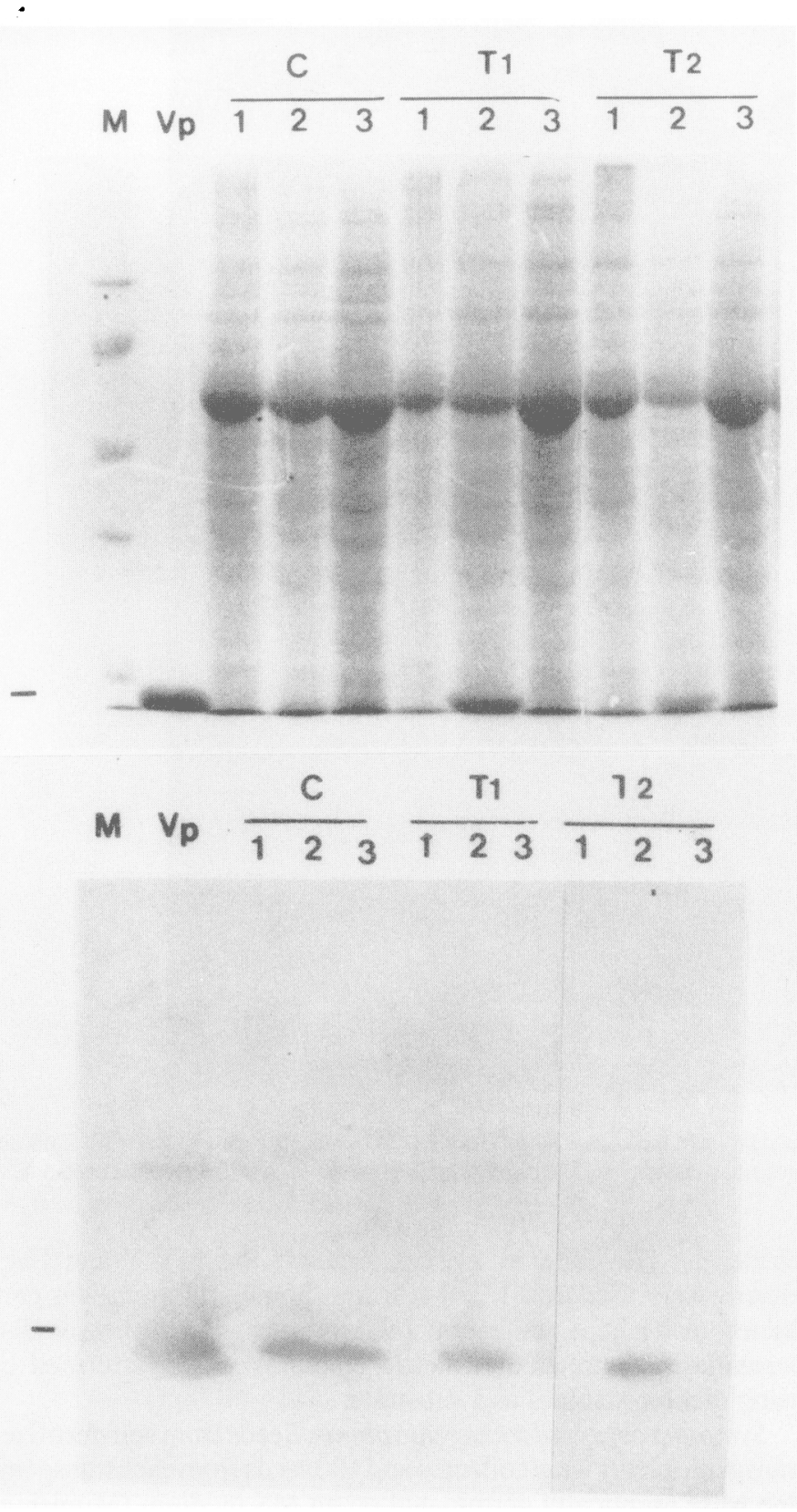

Fig. 3. Immunoblot analysis of nontransformed and transgenic petunia plants inoculated with TMV. Upper panel: purified TMV virions $(\mathrm{Vp})$, total plant proteins from control (C) and transgenic (T1 and T2) plants stained with Coomassie brilliant blue. Lower panel: Immunoblot analysis with polyclonal TMV antiserum. M designates low molecular weight markets from BRL (top to bottom 97.4, 66.2, 45.6, 31, 21.5, and $14.4 \mathrm{kDa}$ ). Lanes 1,2 and 3 correspond to non-inoculated plant, inoculated primary leaves, and non-inoculated apical leaves. Bar indicates the position of the TMV coat protein.

nontransformed control plant were mock-inoculated. After rinsing the inoculated leaf surface with tap water, the plants were grown in the greenhouse at 25C. Symptom development was monitored on a daily basis for 2 months after inoculation.

\section{Results}

Integration of CMV satellite RNA cDNA in petunia plants. Transformed petunia plants were regenerated from A. tumefaciensinfected leaf disks, and 24 primary transformants were selected. Transformed plantlets were analyzed for the presence of the CMV
A)

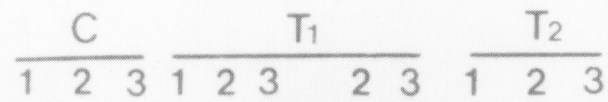

B)
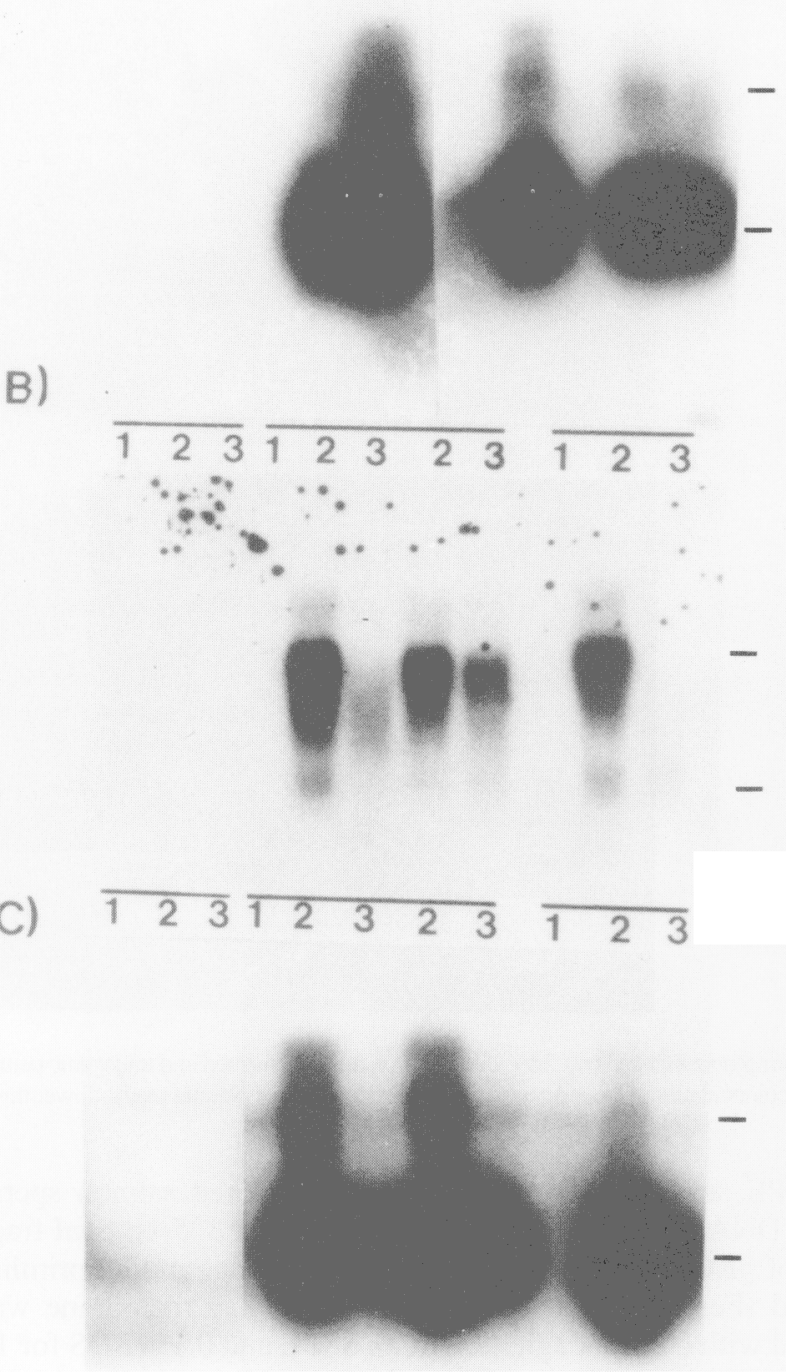

Fig. 4. Northern blot analysis of the CMV satellite RNA accumulation in 20 days post-inoculated petunia. (A) Inoculated with CMV only (B) inoculated with TMV only (C) co-inoculated with CMV and TMV. RNA was extracted from nontransformed (C) and transgenic (T1 and T2) petunia plants. Lane illustration is as same as in Fig. 3. Probe was a 32P-labeled 335 bp ScaI cDNA fragment of CMV satellite RNA. Upper bar indicates the position of 1000-bp transcripts and lower bar, 335-bp unit length transcripts.

satellite RNA sequence by Southern blot hybridization (Fig. 1). Using a 32P-labeled cDNA insert (335-bp ScaI fragment, Fig. 1B) as a probe, fragments of $0.3,0.8$, and $1.3 \mathrm{~kb}$ were detected in Scal digests of genomic DNA isolated from transgenic plants, lines 1 and 2 (Fig. 1A). In addition, transgenic lines 1 and 2 showed two and three additional hybridizing fragments, respectively, suggesting that two or more copies of the T-DNA were inserted in these transgenic plants. No hybridization signals were observed in genomic DNA isolated from nontransformed plants. Thus DNA blot hybridization data confirmed the presence of the cDNA copy of CMV satellite RNA in the genome of transgenic petuniaplants.

Symptom suppression in transgenic petunia plants upon virus 

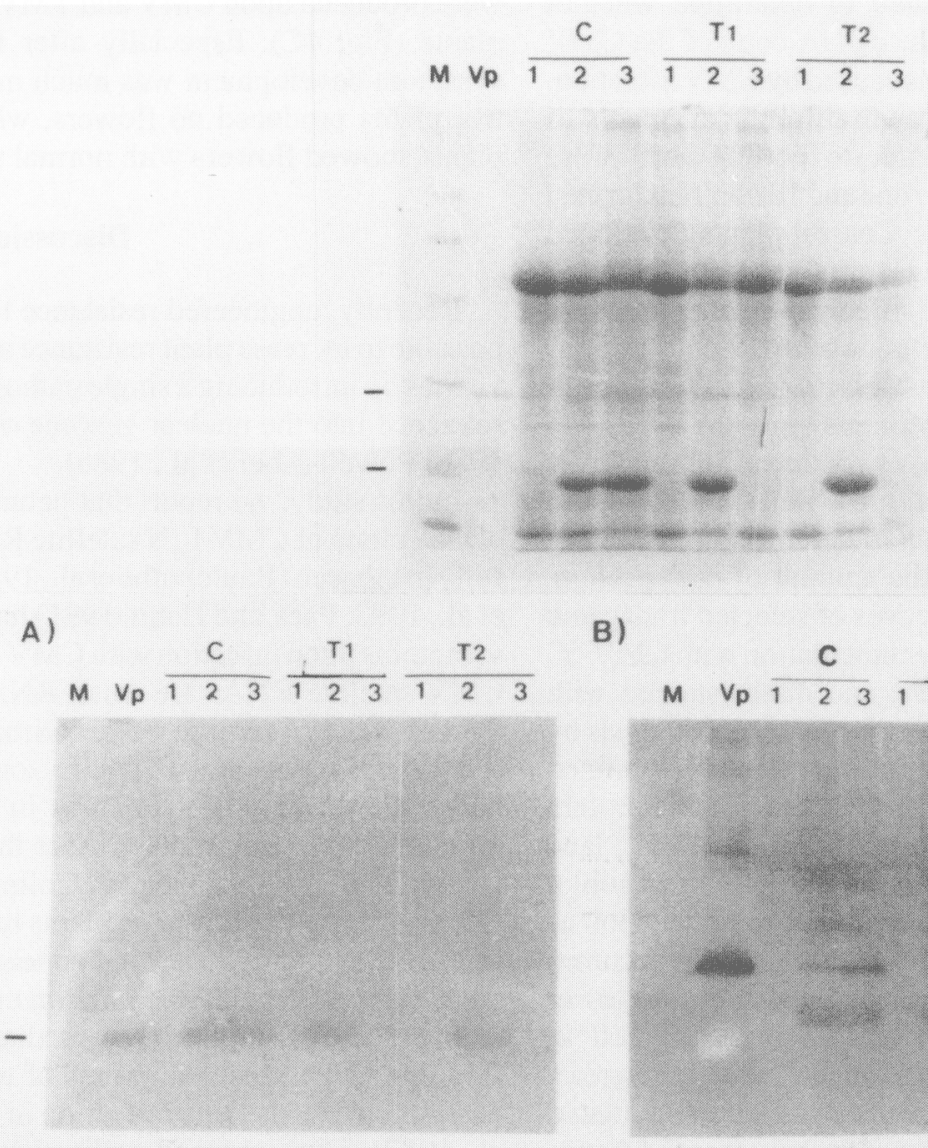

B)

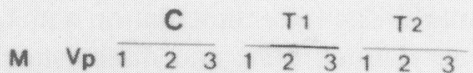

Fig. 5. Immunoblot analysis of the viral protein accumulation in nontransformed and transgenic petunia plants 20 days postcoinoculation with CMV and TMV. Upper panel, total proteins stained with Coomassie brilliant blue. Vp, puirified CMV virion; Lower panel (A): immunoblot analysis with TMV antiserum. Vp-purified TMV virion Lower panel (B): immunoblot analysis with CMV antiserum. Vp, purified CMV virion. Lane illustration is same as in Fig. 3.

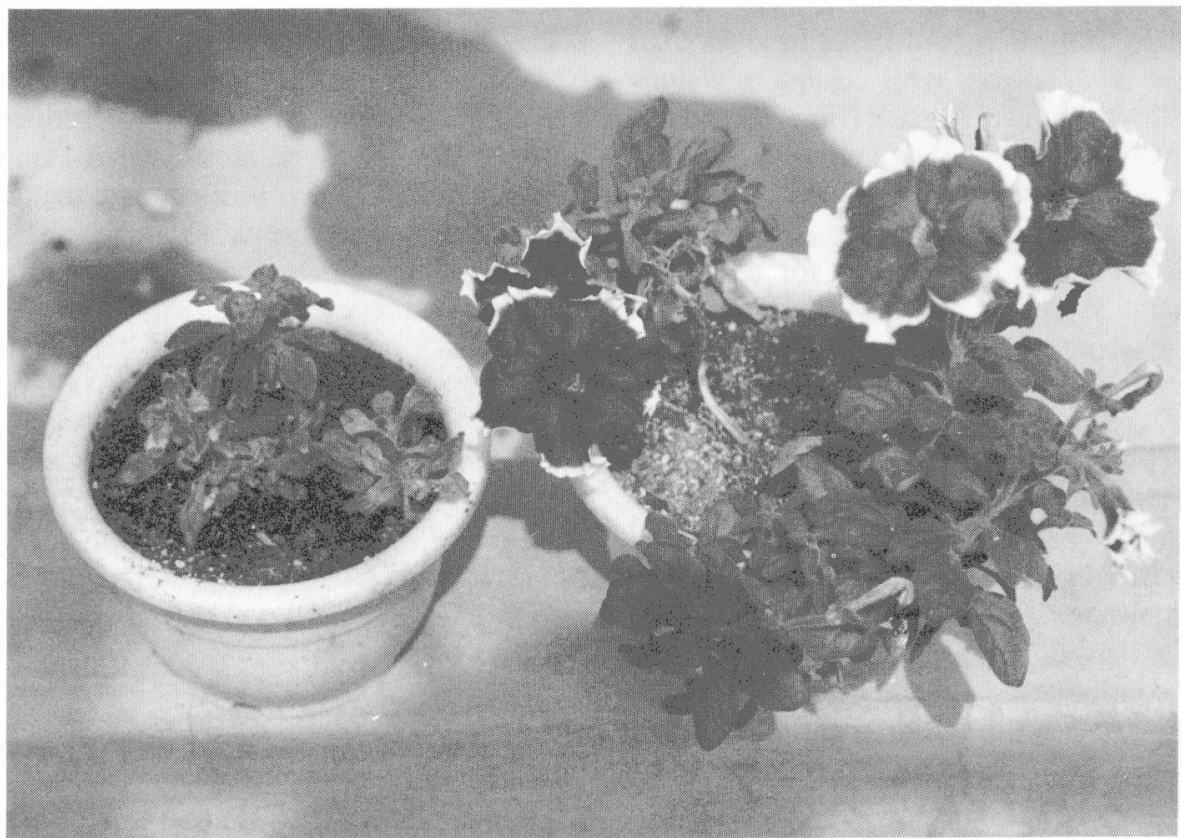

Fig. 6. Symptoms induced in nontransformed (left) and transgenic petunia (right) 2 months after coinoculation with CMV and TMV. 
inoculation. Experiments were initiated to determine whether transgenic petunia plants containing the cDNA copy of the CMV satellite RNA could suppress symptoms caused by CMV infection. To minimize the bias due to plant growth differences, plants of similar height $(\approx 3$ weeks after transfer to potting soil) were selected; 10 plants from each transgenic line-and 10 nontransformed plants were inoculated with CMV-Y. Control plants developed typical yellow mosaic and leaf-curling symptoms within 1 week after inoculation followed by systemic infection leading to severe necrosis. Control and transgenic plants developed chlorotic lesions in. inoculated leaves. However, only two or three apical leaves developed mild mosaic and mottling symptoms after 10 to 14 days in transgenic plants. New leaves produced subsequently showed no mosaic symptoms and plants grew well (Fig. 2 a and b).

We conducted immunoblot analysis to determine if symptom suppression reflected a reduction in the amount of coat protein. Protein extracts were prepared from leaves of selected transgenic and nontransformed plants 20 days after inoculation with CMV-Y, run on $10 \%$ SDS-polyacrylamide gels, and either stained with Coomassie brilliant blue or processed for irnmunoblot analysis by using antiserum to CMV virions. Coomassie brilliant blue stained gels showed that approximately equal amounts of soluble protein extracts were loaded onto gels for each sample except for T1 lane 1 (noninoculated control), which had less protein. The immunoblot analysis revealed that a protein migrating at the same position as the purified CMV and reacting with the CMV antiserum accumulated in inoculated leaves of transgenic lines 1 and 2, but at a lower level than in the control. No viral protein was detected in noninoculated apical leaves of transgenic lines 1 and 2; whereas, CMV coat protein was detected in inoculated and noninoculated apical leaves of control plants. These results show that the symptom delay and perhaps suppression observed upon CMV infection in transgenic plants was accompanied by some reduction in viral protein content, at least in apical leaves of transgenic petunia.

To test the susceptibility of transgenic petunia expressing the CMV satellite RNA cDNA to an unrelated virus, 10 plants from each transgenic line and 10 nontransformed plants were inoculated with TMV. Upon TMV inoculation, nontransformed plants showed veinyellowing and mild leaf distortion (milder symptoms than those observed with CMV inoculation), while transgenic lines showed less severe veinyellowing and distortion (Fig. $2 \mathrm{C}$ and D). We conducted immunoblot experiments using a polyclonal TMV antiserum to confirm the visual observation and found that TMV $\mathrm{CP}$ production was also reduced in apical leaves of transgenic plants (Fig. 3). Since TMV is not a helper virus for the CMV satellite RNA, the production level of CMV satellite RNA transcripts was examined by Northern blot analyses in these plants upon TMV inoculation. At the RNA level, as expected, large amounts of unit length transcripts (335 bp) accumulated in CMVinfected transgenic plants (Fig. 4A). However, transcripts $\approx 1,000$ $\mathrm{bp}$ in size accumulated in TMV-infected transgenic plants (Fig. 4 B). In this case, overexposure was necessary to show $1 \mathrm{~kb}$ transcripts. Since pRok1/105 contains 2.3 copies of the satellite RNA cDNA, a 1000-bp size transcript corresponds to transcripts driven by the CaMV $35 \mathrm{~S}$ promoter.

When nontransformed control petunia plants were co-infected with CMV and TMV, symptoms were much more severe compared to single viral infections. Severe symptoms including necrosis, severe leafcurling, and severe growth retardation were observed (Fig. 2 E and F). In transgenic plants, symptom development was less severe and was accompanied by reduced accumulation of CMV and TMV coat protein in Western blot analysis (Fig. 5). At the RNA level, large amounts of unit length satellite RNA were produced upon CMV and TMV co-inoculation in transgenic plants (Fig. 4C). Especially after flowering, the difference of symptom development was much more evident. Inoculated control plants produced no flowers, whereas inoculated transgenic plants showed flowers with normal shape and color (Fig. 6).

\section{Discussion}

Recently, engineered resistance to virus infection has made it possible to increase plant resistance against otherwise devastating viruses by introducing a single pathogen-derived or virus-targeted sequence into the nuclear genome of the host (Baulcombe et al., 1986; Powell-Abel et al., 1986).

In this study, we report that petunia plants transformed with a cDNA clone of $\mathrm{CMV} \mathrm{I}_{17} \mathrm{~N}$ satellite RNA previously used successfully in tobacco (Baulcombe et al., 1986; Harrison et al., 1987; Kim et al., 1992; Pack and Hahn, 1991) have exhibited delayed disease symptoms upon infection with CMV and TMV, an unrelated virus. CMV satellite RNAs are small RNAs that are not infectious by themselves and require helper viruses for their replication and encapsidation (Simon, 1988). In some cases, satellite RNAs enhance the severity of symptoms in conjunction with the helper virus infection, and in other cases the symptoms are ameliorated (Jaegle et al., 1990; Kaper and Collmer, 1988). The expression of satellite RNAs in transgenic plants has decreased virus symptoms and/or titers in a manner that appears to mimic a natural system (Baulcombe et al., 1986; Harrison et al., 1987).

In the case of satellite RNA-mediated protection, CMV satRNA also protects against symptoms of tomato aspermy virus (TAV) but without causing any reduction in virus replication (Harrison et al., 1987). Thus, reduced replication may not be the sole mechanism of satRNA-mediated protection. Satellite tobacco ring spot virus (sTRSV) also interferes with the replication and disease spread of yet another nepovirus, cherry leafroll virus, even though cherry leafroll virus is not a helper virus for sTRSV (Ponz et al., 1987). In this study, the production of CMV satRNA in transgenic petunia enhanced disease protection against not only CMV but also TMV. In TMV-infected plants, transcripts of $\approx 1 \mathrm{~kb}$ (Fig. 5B) accumulated instead of single unit-length transcripts (335 bp) in CMV-infected plants. Western blot analysis also confirmed that TMV coat protein production was reduced in transgenic plants upon TMV infection. However, it remains to be determined whether ELISA assays will confirm the quantities of coat protein levels expressed in these plants and whether protection was achieved by interference of viral multiplication at the RNA level. As the number of plants used in the virus protection assay was rather small (10 of each transgenic lines), further experiments will be required to assess the CMV satellite RNA-mediated protection against the TMV infection. Furthermore, the mechanism of protection needs to be investigated particularly to ascertain whether it is a simple tolerance or a true resistance. However, our results clearly indicate that transgenic petunia plants expressing the CMV satellite RNA cDNA exhibited delayed symptom expression and possibly protection from infection with CMV and TMV, an unrelated virus.

\section{Literature Cited}

An, G. 1987. Binary Ti vectors for plant transformation and promoter analysis. Meth. Enzymol. 153:292-305.

Baulcombe, D. C., G.R. Saunders, M.W. Bevan, M.A. Mayo, and B.D. Harrison. 1986. Expression of biologically active viral satellite RNA from the nuclear genome of transformed plants. Nature 321:446-449.

Beachy, R.N., S. Loesch-Fries, and N.E. Turner. 1990. Coat protein mediated resistance against virus infection. Annu. Rev. Phytopathol. 
28:451-474,

Bimboim, H.C. 1983. A rapid alkaline extraction method for the isolation of plasmid DNA. Meth. Enzymol. 100:243-255.

Buck, K.W. 1991. Virus resistant plants, p. 136-172. In: D. Grierson (ed.). Plant genetic engineering. vol. 1. Blackie and Son Ltd., Glasgow, Scotland. Chomczynski, P. and N. Sacchi. 1987. Single-step method of RNA isolation by acid guanidium thiocyanate-chloroform extraction. Anal. Biochem. 162:156-159.

Collmer, C.W. and S.H. Howell. 1992. Role of satellite RNA in the expression of symptoms caused by plant viruses. Annu. Rev. Phytopathol. 30:419-442.

Dellaporta, S. L., J. Wood, and J B. Hicks. 1983. A plant DNA minipreparation: Version II. Plant Mol. Biol. Rpt. 1:19.

Feinberg, A.P. and B. Vogelstein. 1983. A technique for radiolabeling a DNA restriction endonuclease fragment to high specific activity. Anal. Biochem. 72:248-254.

Francki, RI.B. 1985. Plant virus satellites. Annu. Rev. Microbiol. 39:151174

Fraser, R.S.S. 1986. Genes for resistance to plant viruses. CRC Crit. Rev. Plant Sci. 3:257-294.

Fritsch, C. and M.A. Mayo. 1989. Satellites of plant viruses, p. 289-321. In: C.L. Mandahar (ed.). Plant viruses, structure and replication. vol. 1. CRC Press, Boca Raton, Fla.

Gould, A.R. and R H. Symons. 1977. Determination of the sequence homology between the four RNA species of cucumber mosaic virus by hybridization analysis with complementary DNA. Nucleic Acids Res. 4:3787-3802.

Harrison, B D., M A. Mayo, and D.C. Baulcombe. 1987. Virus resistance in transgenic plants that express cucumber mosaic virus satellite RNA. Nature 328:799-802.

Hayes, R.J. and K.W. Buck. 1990. Complete replication of a eukaryotic virus RNA in vitro by a purified RNA dependent RNA polymerase. Cell 63:363-368.

Horsch, R. B., J.E. Fry, N L. Hoffman, D. Eichholtz, S G. Rogers, and R.T. Fraley. 1985. A simple and general method for transferring genes into plants. Science 227: 1229-123 1.

Jaegle M., M. Devic, M. Longstaff, and D.C. Baulcombe. 1990. Cucumber mosaic virus satellite RNA (Y strain) analysis of sequences which affect yellow mosaic symptoms on tobacco.J.Gen.Virol.71: 1905-19 12.

Kaper, J.M. and C.W. Collmer. 1988. Modulation of viral plant diseases by secondary RNA agents, p. 17 1-1 94. In: RNA Genetics, variability of RNA genomes. vol. 3. CRC Press, Boca Raton, Fla. E. Domingo, J.J. Holland, and P. Ahlquist (eds.).

Kim, S. J., K.W. Hahn, B.G. Kang, B.D. Kim, and K.-H. Pack. 1992. Progeny analysis of transgenic tobacco plants that express cucumber mosaic virus satellite RNA. Korean J. Plant Tissue Cult. 19:159-165.

Kuwata, S., C. Masuta, and Y. Takanami. 1991. Reciprocal phenotype alterations between two satellite RNAs of cucumber mosaic virus. J. Gen. Virol. 72:2385-2389.
Lowry, O. H., N.Y. Rosenbrough, A.L. Farr, and R.Y. Randall. 1951. Protein measurement with the Folin phenol reagent. J. Biol. Chem. 193:265-275.

Masuta, C. and Y. Takanami. 1989. Determination of sequence and structural requirements for pathogenicity of a cucumber mosaic virus satellite RNA (Y-sat RNA). Plant Cell 1:1165-1173.

Mossop, D.W. and R. LB. Francki. 1979. Comparative studies of two satellite RNAs of cucumber mosaic virus. Virology 95:395-404.

Murant, A F., and LK. Kumar. 1990. Different variants of the satellite RNA of groundnut rosette virus are responsible for the chlorotic and green forms of groundnut rosette disease. J. Gen. Virol. 69: 1479-1486.

Murashige, T. and F. Skoog. 1962. A revised medium for rapid growth and bioassays with tobacco tissue cultures. Physiol. Plant 15:473-497.

Naidu, R. A., G.B. Collins, and S.A. Ghabrial. 1991. Symptom-modulating properties of peanut stunt virus satellite RNA sequence variants. Mol. Plant-Microbe Interact. 4:268-275.

Nitta, N., Y. Takanami, S. Kuwata, and S. Kubo. 1988. Inoculation with RNAs 1 and 2 of cucumber mosaic virus induces viral RNA replicase activity in tobacco mesophyll protoplasts. J. Gen. Virol. 69:2695-2700.

Pack, K.-H. and K.W. Hahn. 1991. Development of virus resistance in transgenic tobacco plants that express the cucumber mosaic virus satellite RNA. Mol. Cells 1:295-300.

Palukaitis, P. 1988. Pathogenicity regulation by satellite RNAs of cucumber mosaic virus: minor nucleotide sequence changes after host responses. Mol. Plant-Microbe Interact. 1: 175-181.

Peden, K. W. and R. H. Symons. 1973. Cucumber mosaic virus contains a functionally divided genome. Virology 53:487-492.

Ponz, F., A. Rowhani, S.M. Mircetich, and G. Bruening. 1987. Cherry leafroll virus infections are affected by a satellite RNA that the virus does not support. Virology 160: 183-1 90.

Powell-Abel, P., R.S. Nelson, B. De, N. Hoffmann, S.G. Rogers, R.T. Fraley, and R.N. Beachy. 1986. Delay of disease development in transgenic plants that express the tobacco mosaic virus coat protein gene. Science 232:738-743.

Rizzo, T.M. and P. Palukaitis. 1988. Nucleotide sequence and evolutionary relationships of cucumber mosaic virus (CMV) strains: CMV RNA2. J. Gen. Virol. 69: 1777-1787.

Sambrook, J., E. F. Fritsch, and T. Maniatis. 1989. Molecular cloning: A laboratory manual. 2nd ed. Cold Spring Harbor Laboratory, Cold Spring Harbor.

Simon, A.E. 1988. Satellite RNAs of plant viruses. Plant Mol. Biol. Rpt. 6:240-252.

Towbin, H., T. Stachelin, and J. Gordin. 1979. Electrophoretic transfer of proteins from polyacrylamide gels to nitrocellulose sheets: Procedure and some applications. Proc. Natl. Acad. Sci. USA 76:4350-4354.

Wu, G., J. M. Kaper, M.E. Tousignant, C. Masuta, S. Kuwata, Y. Takanami, L. Pena, and J.R. Diaz-Ruiz. 1993. Tomato necrosis and the 369 nucleotide Y satellite of cucumber mosaic. virus: Factors affecting satellite biological expression. J. Gen. Virol. 74:161-168. 